\title{
The Balanced Participation Model: sharing opportunities for giving people with early- stage dementia a voice in research
}

\begin{abstract}
Much has been written about the stigmatisation and discrimination ascribed to people with dementia in society and in research. This marginalisation has led to a silencing of their voices and their experiences both on a national and international scale, and an often limited understanding about how people with dementia experience daily life. In this study a participatory research project was conducted in collaboration with people with early-stage dementia who attended an adult school in Denmark. The study explored how to work collaboratively with people with dementia to develop their own research projects. Based on the findings, a qualitative participatory research model has been designed to support the active engagement of people with early-stage dementia in research. The project involved 12 people with early-stage dementia, who were divided into two groups ( $n=6$ in each group) and then trained in research skills. Each group was then supported to design, develop, and undertake a group research project. This was one continuous process, and constantly took account of the individual competencies of each group member. Based upon the knowledge gained from the training in research skills and the participatory research project The Balanced Participation Model was developed. The model illustrates five phases in a participatory research process focusing on the considerations needed for participant recruitment, planning, training in research skills, the participatory research project, and the evaluation and dissemination of results. The core of the model highlights the importance of the researcher role in facilitating the collaboration.
\end{abstract}

\section{Introduction}

Much has been written about the stigmatisation and discrimination ascribed to people with dementia in society (Alzheimer Europe, 2013; McParland, Kelly, \& Innes, 2017). Consequently, this marginalisation may lead to social isolation, exclusion and loss of control over life decisions (Nomura, 2009; Tanner, 2012). Further, it can negatively affect self-confidence, self-esteem and quality of life and lead to anxiety, 
depression and further social withdrawal (Clare \& Woods, 2008; Nomura, 2009; Tanner, 2012). The voices of people with dementia are also absent from much existing research, leading to further marginalisation of their voices and experiences in a range of professional and academic contexts. The inclusion of people with dementia in research affords us opportunities to enhance our understanding of what it is like to live with dementia and how societies can better support this group, reducing stigma and discrimination (Dewar, 2005).

Researching with, rather than 'on' or 'for' people with dementia is not only ethically important, but is essential to ensure that projects, including the questions and aims which underpin them, reflect the most pressing gaps in existing evidence as defined by people with dementia themselves (INVOLVE, 2018). Positively within the last decade, moves towards more person-centred research have resulted in increased acknowledgement that people with dementia have rights, including rights for being involved in research and sharing their experiences of dementia (Mckillop, 2004; Wilkinson \& Hubbard, 2003). Furthermore, it is recognised that they can make a valuable contribution to research as active participants, whilst simultaneously benefitting from their involvement through empowerment and inclusion (Dewing, 2007; Hellström, Nolan, \& Lundh, 2007; Hubbard, Downs, \& Tester, 2003; Pipon Young, 2012). Even with this increasing awareness, there exists a paucity of research which involves people with dementia in identifying their own research priorities (Kelly et al., 2015; Law, 2013), and therefore directly contributing to changes in research into dementia prevention, treatment and care (Dewar, 2005).

This article presents a study which demonstrates how the voices of people with dementia can be heard in research. The outcome was to develop a participatory research model to enable more people with dementia to be involved in future research and ensuring their voices are heard. This study was based in Denmark; however, the findings are useful for anyone wishing to collaborate with people with dementia in a research context.

\section{Theoretical background}

\section{Participatory and emancipatory research}

Research projects where participants are supported to influence design and completion are often defined as participatory or emancipatory research. Here the researcher works in partnership with participants to gather insights into their world (Keady, Williams, \& Hughes-Robets, 2005). It differs from conventional research as 
the ideological stance and emphasis of the researcher's values and premises are made explicit and the research is undertaken with active participation and control of the participants (Tandon, 2005).

Participatory and emancipatory research are two distinct, but complementary approaches (Traina, 2014; Wilkinson, 2002). Often, participatory research is defined by actively involving the participation of all partners throughout all stages of the research process - from research design, to knowledge production, to dissemination - with the aim of transforming people's lives (Conder, 2011a). It supports socially marginalised people to critically investigate and analyse their reality and undertake collective actions to bring constructive changes into their lives (Tandon, 2005). Positively, participatory research can be transformative; participants can be equipped to make sustainable personal changes and challenge structural inequalities (Knobzi \& Flicker, 2010). In this perspective, the researcher has to maintain a close relationship with the participants throughout the study (Keady et al., 2005). Participatory research has roots back to social science, influenced by adult teaching and development programs of (for example) agriculture and communities. Many of the techniques applied in participatory research stem from Paulo Freire's work in education (Cornwall \& Jewkes, 1995). Also, the fields of learning difficulties, disability and feminism research have contributed to the paradigm since the 1990's (Faulkner, 2004). Research in mental health has also long since incorporated participatory, user-controlled and user-led research (Dupuis, Gillies, \& Carson, 2012).

Whilst participatory research fulfils the paradigm of active citizenship, emancipatory research is more strictly connected with a lack of rights (Traina, 2014), implying a departure from a deficit model of communication between researchers and citizens. Knowledge is not seen as a privilege of academic institutions, but rather it is coproduced with participants and a tool used to improve people's rights and liberation (Traina, 2014). It has its genesis in the social model of disability (Traina, 2014) and in the growth of the Disability Movement, the raising awareness of the disillusion of positive and interpretive research paradigms in the 1960s (Traina, 2014). Emancipatory research is changing "the social relations of research, trying to place the control in the hands of researched, not researcher" (Barnes \& Mercer, 1997, p. 17). The aim is to transform the culture and the context and to reflect the perspectives of people - seeking liberating and emancipatory outcomes by putting more control in the hands of participants, rather than researchers (Barnes \& Mercer, 
1997). In this way, individuals are re-defined as the co-creators of research, rather than its subjects (Traina, 2014).

As a research approach, participatory research is relatively new. It is, however, gaining increasing momentum within qualitative research in English-speaking countries (Bergold \& Thomas, 2012; ). It offers a range of approaches including participatory action research, community-based participatory research, participatory rural appraisal, participatory design and others (Blumenthal, 2011; Cornwall \& Jewkes, 1995; Ehde et al., 2013; Hanson et al., 2007; Knobzi \& Flicker, 2010; Stacciarini, Shattell, Coady, \& Wiens, 2011). In part, this diversity of approaches means that participatory research as a term is difficult to navigate because of a plethora of different and allied definitions, methods and models which exist (Staniszewska, 2009; Ward, 2009). It means a variation of concepts and terminologies which limit consistency and clarity, leading to relevant criticism from more conventional research (Thoft, 2017).

In the current article, participatory research is understood as an approach in which participants take part in and influence the research process, resulting in a collaborative production of knowledge. We argue, however, that true participation can be realised to different degrees (Arnstein, 1969) and may include tensions and ethical or epistemological dilemmas, which require continuous reflection in the research process.

\section{Dementia and participatory research}

Until the 1990s, dementia was typically described from a medical perspective, which portrayed those with dementia as having diseased brains rather than focussing on them as individuals with aspirations, needs and experiences (Wilkinson, 2002). People with dementia were viewed as unable to contribute to an understanding of the condition, and as passive receivers of care, rather than active agents in their own right (Dupuis et al., 2012; McParland et al., 2017; Pipon Young, 2012). Research has also focused on the stress and burden of family carers and their point of view, overlooking the voices of those with dementia as the validity of studies that investigated their perspective was questioned (Knight, Lutzky, \& Macofsky-Urban, 1993; Wilkinson, 2002).

One of the pioneers in challenging the medical perspective was the psychogerontologist, Thomas Kitwood, who argued that every person with dementia is a meaning-maker, who forms opinions and understandings of actions (Kitwood, 1997). 
This move to a more person-centered, rights-based approach has also been seen in dementia research, illustrating an increasing acceptance in research that the views of people with dementia need to be included (Mckillop, 2004; Wilkinson, 2002; Wilkinson \& Hubbard, 2003). Regardless of this, until 2000, studies which sought personal perspectives on dementia were relatively sparse (Clarke \& Keady, 2002).

This is also the case when looking at applying participatory approaches in dementia studies as multiple ethical frameworks, guidelines and systems of protection around people with dementia might reduce rather than increase their opportunities to have a voice in research (Burns, Hyde, Killett, Poland, \& Gray, 2014). This can erode the group's autonomy and contribute towards a process of infantilisation (Hellström et al., 2007). It is therefore important to identify ways that enable people with dementia to be involved in participatory research in a moral and ethical way regardless of the obstacles there might be. Participatory research can lead to empowerment and rehabilitation, enabling people with dementia who participate, to change their view on the illness through acceptance, hope and experience of empowerment; getting a feeling of control in their lives by understanding more about dementia (Dupuis \& Gillies, 2014, Thoft, 2017).

However, an obstacle in participatory research is that marginalised groups often lack sufficient research knowledge and skills to undertake the role. Other barriers are culture, language, poor health, lack of resources and education (Fudge, Wolfe, \& McKevitt, 2007). Training in research methods and research processes are necessary to ensure people with dementia feel comfortable to take part (Bergold \& Thomas, 2012; Dupuis et al., 2012). Unfortunately, formal models of training to enable true participation are scarce, and models which focus specifically on the needs of people with dementia are noticeably absent (Bergold \& Thomas, 2012; Conder, 2011b; Dupuis et al., 2012). It has been suggested that this may in part be because of perceptions that the condition could preclude individual participation (Yu, 2009). However today, it is acknowledged that the cognitive impairment of people with dementia is a product of multiple factors and individual differences, meaning that people with dementia have different cognitive reserves and capacities (Winblad et al., 2016). Thus, training is possible, but more knowledge about how to train people with dementia is needed (Tanner, 2012). Following an in-depth literature review, only two models of this kind were identified Partners in Projects (Parkes et al., 2014) and Authentic partnerships (Dupuis et al., 2012). Literature searching was carried out using PubMed, Chinahl, Cochrane Library and Web of Knowledge. A block search 
with the keywords; participatory research, qualitative research, dementia and training was conducted. Also, government, third sector, and charitable websites were searched for relevant grey literature meeting the overall search terms.

Nevertheless, a critical stance must be taken when considering applying training within the research process itself. The application of training can serve to situate participants as subjects requiring development, marginalise local knowledge and subsequently lead to tensions between expecting people to employ recognised research skills on the one hand and honouring and facilitating their unique contribution on the other (Reed, Cook, Bolter, \& et al., 2006). Training can produce disciplined participants so that the researchers' control is retained (Littlechild, Tanner, \& Hall, 2015; Milligan, 2015) with a tokenistic collaboration result. It is therefore important to remain reflexive and critical throughout the research process (Carey, 2010; Milligan, 2015) as participatory research does not per se guarantee better data, improved understandings, democratising processes or power-free relations between researcher and participants (Roy, 2012).

\section{Methods: Developing a qualitative participatory research model}

\section{Participatory research models}

This study aimed to develop a participatory research model drawing from qualitative research about the lifeworld perspectives of people with early-stage dementia. In the study the participants were trained in research skills to enable them to conduct participatory research projects in collaboration with the researcher. The study was inspired by the two identified participatory research models; Partners in Projects (Parkes et al., 2014) and Authentic partnerships (Dupuis et al., 2012). Partners in Projects is a generic patient and public involvement (PPI) model which systematically trains people to develop research capability so they can actively and meaningfully engage in research within a health and social care context. The model inspired the development of training in research skills, which we discuss further below. It is organised with a central core which focuses on research processes and four supportive themes (Figure 1).

Figure 1: Partners in projects 


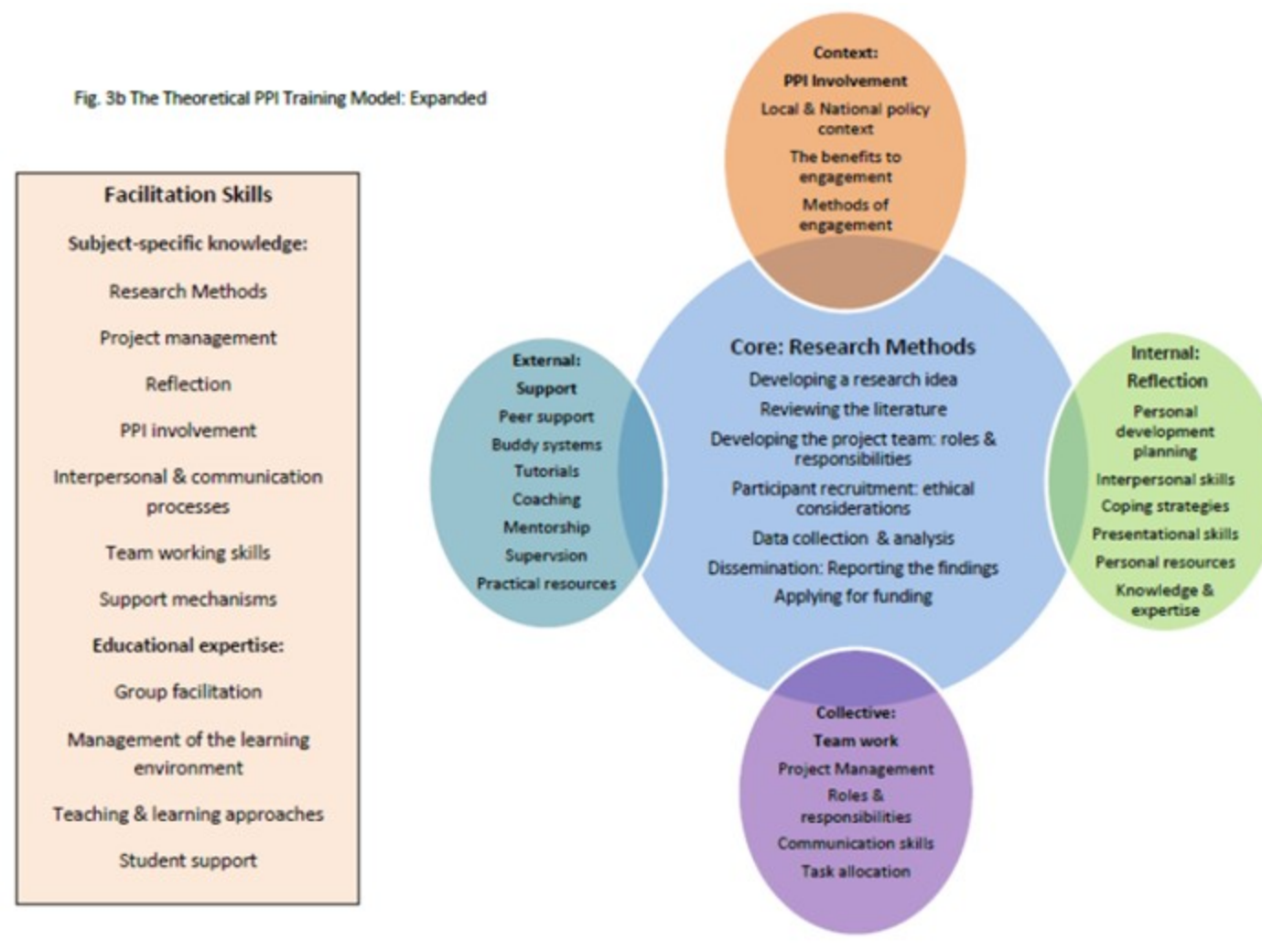

(Parkes, et al., 2014, p. 406)

The Authentic Partnerships (Dupuis et al., 2012) Model was chosen as a supportive framework for this study as it supplemented the training model by focusing on constructive collaboration with people with dementia. It reorganises the collective capacity people with dementia have to empower themselves by seeing knowledge as power and education and learning as important vehicles for social change, transformation and liberation. Moreover, the model incorporates a systematic process of critical reflection and dialogue with the partners (Figure 2).

Figure 2: Authentic partnerships 


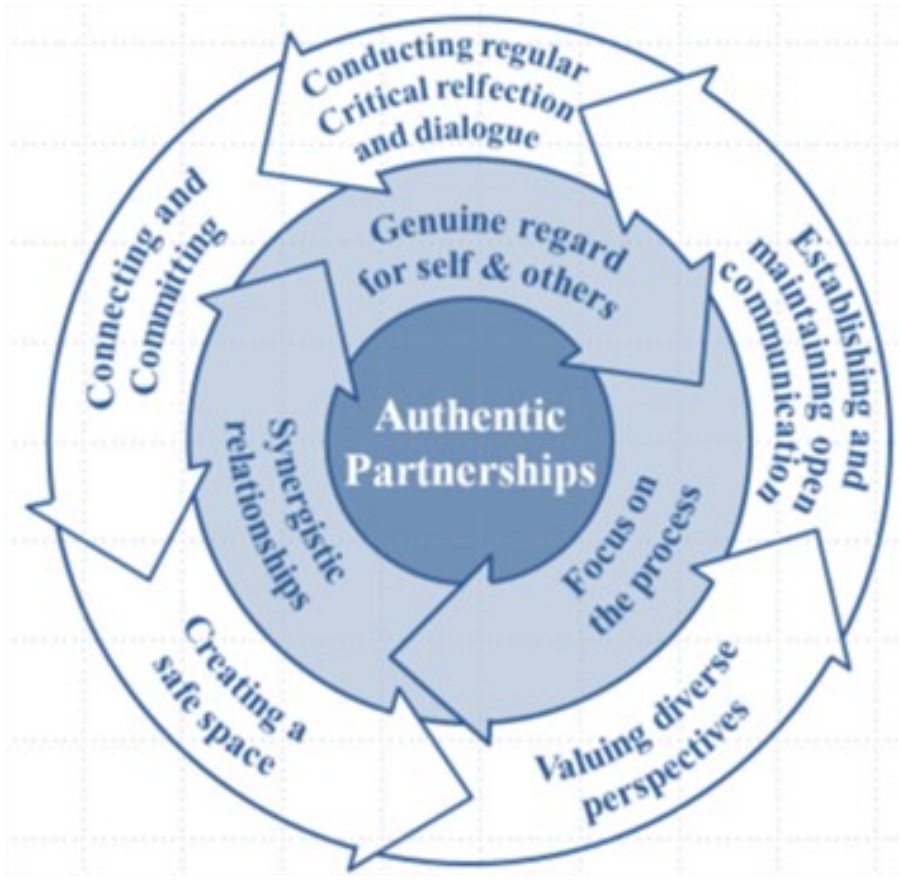

(Dupuis, Gillies et al., 2010 p. 10)

\section{Study structure}

It was not possible to apply all elements of the existing models within the current study because of the attention, memory and language challenges of the participants. The elements of the models which were applied were discussed with both people with dementia and those who worked to support them, to ensure a constructive process. The three-month observational period at the outset of the current study allowed the researcher to reflect on the competences of participants, to introduce the project to them, and to begin discussions on the training component, underpinned by their views and those of the staff who work with them. Examples of how the training was adapted includes the reduction of particular elements, for example; participants were not trained in how to write proposals or applying for funding: they wanted to maintain focus on their current projects. They had no interest in conducting their own projects afterwards as they thought these would not meet the criteria of good research.

To gather an understanding of how useful the training was in supporting people with dementia to work with researchers on a research project, two concurrent peer research projects (one by each group) were undertaken. The development and completion of these projects were embedded within the delivery of the training, for 
example where a training session held on defining a research question, the outcome of the session was the identification of the focus of the study that each group would carry out. These projects were designed, in collaboration with the groups, to be peer-research projects. The groups chose to design their studies in this way in order that they would not need to complete data collection with people who were unfamiliar to them; they felt it was important to know and trust people they worked with (Thoft, 2017). This also offered them the opportunity to act as informants and co-researchers within the same research project, offering a wider view of the research process. In this study, the guiding principles ensured a constructive and conducive collaboration with the participants throughout the training and the participatory research projects (Thoft, 2017).

\section{Participants}

In total, 15 potential participants (65-82 years old) with early-stage dementia were invited to take part in the research. This number was recommended by those in the setting based on their experience of working with the group concerned. The inclusion criteria were: a diagnosis of dementia at least six months before recruitment, deemed as being in an early-stage of dementia progression, could give informed written consent, and awareness of the diagnosis and its implications. The focus of recruitment in the study was on enabling people who had the capacity and willingness to participate an opportunity to be involved. Verbal and written consent was obtained from participants using an ongoing consent process to protect the participants from not being harmed (Dewing, 2007). Three decided not to participate. Examples of the reasons cited for this included escalating experience of cognitive decline and acute illness in the family. Twelve (65-82 years old) people with early-stage dementia participated in the study. They were recruited from the Adult School VUK (Voksenskolen for Kommunikation og Undervisning) in Denmark (VUK, 2013; Ward, Sørensen, Kousgaard \& Thoft, 2018; Ward, Thoft, Lomax \& Parkes, 2018). This school centres on compensatory special education for adults, with a focus on lifelong learning regardless of functionality and on individual resources rather than diagnosis. At VUK, people with early-stage dementia are called students. They receive cognitive training and stimulation, physical training, and training in various creative disciplines at the school (VUK, 2013; Ward, Sørensen, Kousgaard \& Thoft, 2018; Ward, Thoft, Lomax \& Parkes, 2018). VUK was selected as the setting because it allowed collaboration with participants who knew each other in advance in an environment well-known to them. Prior to the 
participatory research project, the researcher had a three-month observation period at the school. The study was approved by The Ethics Committee in Northern Denmark on the $28^{\text {th }}$ August 2013 and the Danish Data Agency on the $22^{\text {nd }}$ August 2013 (J.nr. 2013-41-2297).

\section{The participatory study}

The twelve participants chose to be in one of two project groups of six people based upon who they interacted with at VUK. To have two groups ensured it was possible to support the participants and provide training in research skills, which was tailored to their participatory research projects. Here the researcher was both a teacher and a researcher, which was necessary to give the participants skills, so they could understand and confidently and competently contribute to the research process (Cornwall, 2008). At the same time the researcher was a supporter and a learnertuning into the participants and learning in the research process; enabling the research projects to be formed and sculpted to what was relevant for the participants (Thoft, 2017). Participants held two roles as both co-researchers and participants in the two projects. This design enabled them to feel safe and comfortable around the project work, whilst enabling their experiences to be heard. Thus, they pointed out themselves, after they had formulated the inclusion criteria, that they were relevant informants for the research topics they had chosen. Together, this formed the decision of conducting two modified peer-research projects with the participants.

As an introduction, the participants were presented with a folder identical to the researcher's own. This included a work plan to visualise progression through the process. Paragraphs were kept short for clarify, and illustrations, visualisations, drawings and photographs were used to aid cognition. Each session started with the routine of reviewing the contents of this folder, enabling the participants to recall and talk about what they worked on in the last session, and giving them an opportunity to enhance episodic memories (Staniszewska, 2009). In practice, the photographs often prompted their memories about funny episodes related to the session even though the pictures only showed the work completed. Furthermore, a structure for the work was presented which helped the participants to follow and remember the context of the study (Table 1 ).

Table 1: Structure of the work 
- Overall resume of last session supplemented with pictures

- Presentation of the aim of the session

- Presentation and introduction of the content

- Work with the content

- Repetition of the session in headlines

- Resume of results gained

- Verbal evaluation

This structure ensured that the last session's work was repeated with a verbal resume supported by pictures and text in the session papers. Thereafter, new content was introduced, and they worked and finished this content within a session. At the end of each session the headlines of the work were repeated with a summary of the findings. Finally, each session was evaluated with the purpose of changing the way of working if the participants wanted this. This approach was designed to further enable their involvement by supporting their memory, attention and concentration. In total, 9 sessions of $1 \frac{1}{2}-2$ hours length over a three-month period were held in a traditional classroom at VUK, deemed a safe environment by the participants. At the outset of the project, when the sessions were initially planned, staff at the school recommended building in timetabled breaks to the sessions, however during the delivery of the project participants opted to remove these to reduce the possibility that they may forget what they had been working on. The solution, then became small informal breaks that occurred naturally.

The first session focussed on the aim of the project, gaining a mutual understanding of it, and collectively discussing the collaboration. At this stage, the role of the researcher was discussed, and participants requested that this centred on keeping the structure and ensuring that sessions completed on time. In addition to this, the participants invited the researcher to take part, or to facilitate discussions where support was needed.

Session two focused on developing participants' understanding of research. They characterised how they defined it using pictorial representations and drawings and extended this discussion to potential research topics for their own projects. Using 
post-its, the participants voted for the research idea they wanted to work with, and subsequently discussed and agreed their research questions. The researcher did not take part in the vote to identify the topic areas, however did support the development of the subsequent research questions. Session three focussed on the development of inclusion criteria, data collection methods and research ethics. This was challenging for the participants; it reflected a high level of abstract thinking especially around research ethics which they found to be too protective. They were introduced to qualitative and quantitative research and different data collection methods, which were shown visually. It was then up to the participants to choose the methods. Both groups chose to work with interviews with question cards; they deemed that these offered them a useful structure. They thought this would help them to concentrate during the interview regardless of their memory and attention problems. The last session centred on the design of the interview itself, and between five and seven question cards were formulated by the participants in each group. Thereafter, they prioritised the cards with numbers to create a logical structure for them to follow. Finally, the participants worked in pairs to practice how to conduct an individual interview, supported by the researcher who answered their queries and discussed any challenges that they found in delivering the questions in the way that they had planned.

During sessions five to nine, data collection and analysis for the projects were completed. Session five focused on conducting the interviews, which were completed in pairs. All interviews were video recorded to support the researcher in transcribing the interviews. During this process participants needed varying levels of support. Some needed communicative support (word finding) while others needed more structural support (order of question cards). A couple of the participants in each project group needed no support at all, showing a quit impressing overview in the interviews. They helped the other person in the interview and pointed out that an area in the interview already had been covered before the interview question was asked.

In sessions six-nine, transcripts from the interviews were analysed. This proved to be a challenging and time-consuming process. To support the participants the researcher transcribed and condensed the transcripts to an anonymous narrative for each group to enable an overview of the text without too many confusing words and repetitions. The narrative was read for the participants several times. Following this, each person read and highlighted essential sentences in the text supported by 
analytical questions relevant to their research question. Using highlighters served to assist participants to draw out the key points important to them. The researcher wrote the highlighted sentences on post-its and placed them on a board with the purpose to cluster them into themes. Here some participants took the lead because they quickly saw the connections between the post-its. They pointed out overlaps and discussed the suggestions that were made. This was also the case when the groups formulated a summary of each theme. Finally, the themes were interpreted from the perspective of living with dementia and quotes were found for each theme by using same highlighting procedure as for the identification of the themes. The researcher then wrote the themes with quotes into a coherent text, which the groups commented on, and changes were made in accordance with their wishes.

A discussion followed about opportunities to disseminate their results. The participants opted to share their findings with students at VUK, as well as through local press (newspaper and television station). The researcher supported the groups to make these contacts and on the day of the resulting interviews to distil the process and outcomes of the projects alongside the participants themselves.

Data analysis: reflecting on involving people with dementia in participatory research

After the completion and dissemination of the two participatory research projects, the researcher compiled all evaluative data collected during the study (including data collected during evaluative focus group sessions at the end of each session, and observational data recorded through the use of videoed sessions and researcher reflective diary), with the purpose of developing a participatory research model for allowing people with early-stage dementia to be involved as co-researchers in dementia research. This data was uploaded in Nvivo and analysed by using thematic analysis inspired by Braun and Clarke (Braun, Clarke, 2006). The analysis revealed five themes. One theme Others don't have a clue, let's change it, which described the participants' motivation for conducting a research project. The theme You may be our conductor described the participants' need and awareness of support in the research project. The third theme We are still the same even though we are not the same highlighted their experiences with dementia, which were incorporated in the research project. To be with likeminded is liberating described the importance of a positive and supportive relationship. The theme Why does it have to be so negative? focused on the essential of a relaxed and humoristic atmosphere. Finally, the theme It is nice that some will collaborate with us expressed their experiences with being 
involved in a participatory research project. These results offered the opportunity to develop a model of participatory research with people with dementia: The Balanced Participation Model (Thoft, 2017). After the model was developed, it was validated via a discussion process. The model was discussed with one representative of each project group and two teachers from VUK to ensure it addressed relevant aspects for involving people with dementia in research.

\section{Findings: The Balanced Participation Model}

The Balanced Participation Model is offered as a framework for researchers wishing to collaborate with people with early-stage dementia in a research context. The model includes five phases of research, ensuring a constructive collaborative research process (Figure 3).

Figure 3: The Balanced Participation Model

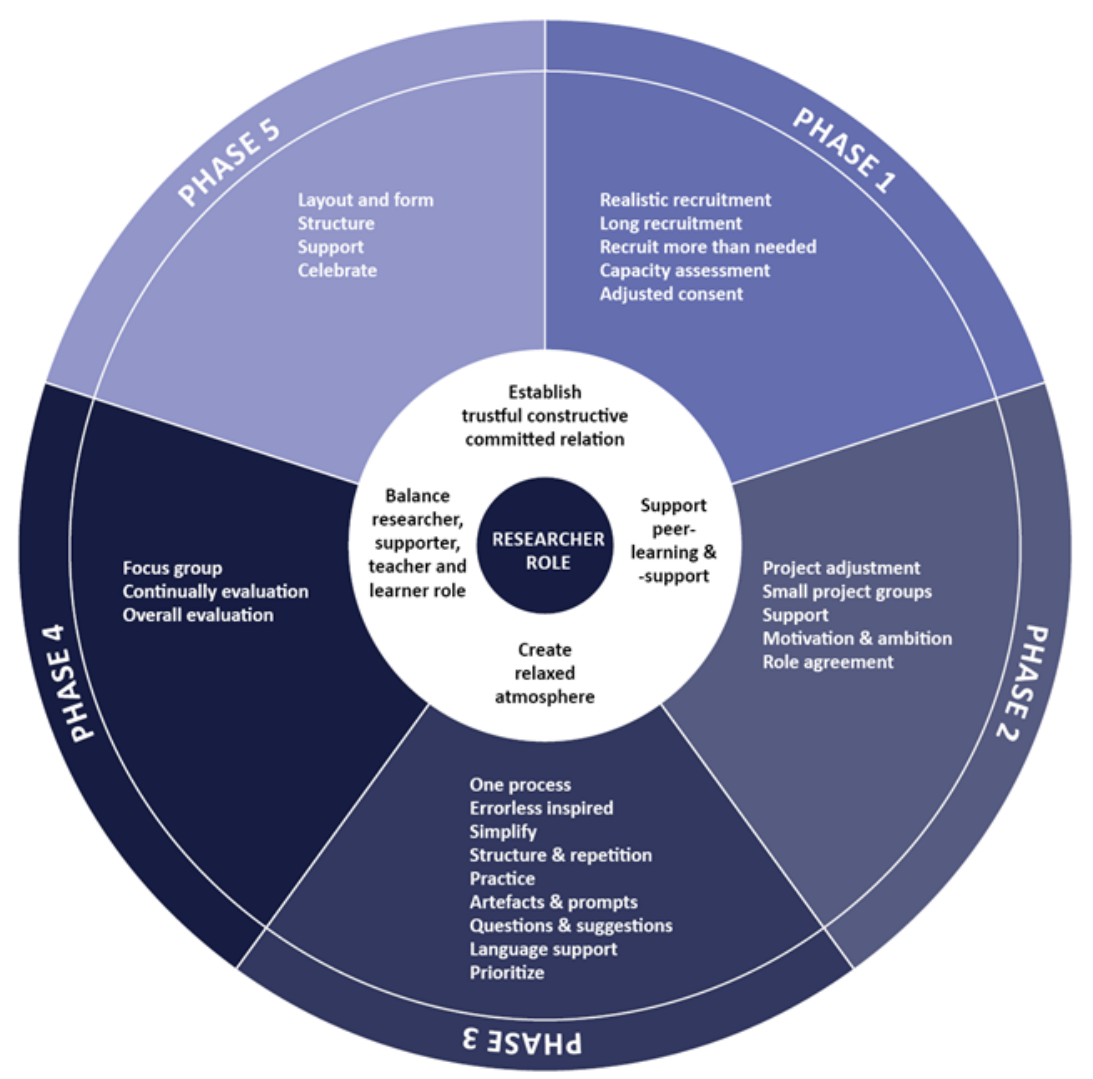

(Thoft, 2017, p. 222)

Phase 1 covers a recruitment and consent period. Here, people with dementia are recruited in accordance with guidelines and frameworks from the organisations through which participants are being recruited, but with a critical view on the 
systems of protection there may exist. It is important that project plans offer flexibility; recruitment periods may be lengthy due to a need to spend time building a rapport with potential participants, explaining and exploring the remit of any proposed project to them. In the study, the researcher e.g. participated in the students' school-activities at VUK. In addition, due to the progressive nature of dementia, the recruitment of a larger sample than normal may be required for the selected methodology. It is preferable to assess the potential participants' capacity to consent in collaboration with professionals who know them. Furthermore, the consent form has to be adjusted to the cognitive capacity of the participants recruited. An ongoing consent process throughout the research project can be considered as long it is modified to address the requirements of each participant.

Phase 2 is a planning and establishing period. Here, the researcher adjusts the participatory research project based upon knowledge about existing participatory models and background knowledge about each participant. It is relevant to establish small project groups, so the participants are comfortable voicing their opinions. If more support is needed, the researcher can invite a professional who knows the participants to attend the project group, as the study showed it is important the participants know those they collaborate with. It is important to identify the motivation, engagement, and ambition of the participants so that all are comfortable with the approach taken. Identifying roles between the participants and researcher also support the relationship within the group. A collaboration agreement can be signed. In the study the researcher wrote down the participants wishes and the role agreement.

In phase 3, the training in research skills and the participatory research projects are completed. Here, final adjustments to the training and participatory research project are made collaboratively with participants. The researcher offers training in research skills and, concurrently, supports the ongoing development of participatory research project(s) to avoid the learning being lost before newly acquired skills are applied. Creating a constructive learning environment ensures that the participants' contributions are acknowledged and interpreted within the project. Simplifying the research skills training and the participatory research project is essential so the participants can conduct the tasks. To support the participants' memory, the same structure can be used throughout the training and participatory research, using objects or images as prompts, and repetition as needed. The structure in the study was deemed successful; several participants predicted what would come next in the 
session. Furthermore, simple, concrete and directive questions and suggestions can support the participants' voice. To enhance communication, using everyday language is advisable, supported with verbal and non-verbal signals. Finally, careful consideration should be given to the content of the training, ensuring that the delivery is as focussed as possible (whilst flexible enough to meet the requirements of participants). Clear and concise communication is essential, with repetition if necessary. Thus, it is important the training does not destroy the unique contribution of people with dementia.

Phase 4 focuses on the evaluation of the research process. The inclusion of this element of the model ensures that data is collected to enable evaluation of the process and outcomes. In this study, focus groups were used to this end in which the researcher acted as a facilitator and moderator. These group discussions among peers enabled promotion of participants' memories. Evaluation also enables realtime adjustments to be made to project design, aligning activities with the changing competences of the groups.

Finally, phase 5 incorporates the dissemination of results. Here, the researcher and the participants collectively decide the layout and format of the dissemination to allow their voices to be included. It is crucial to structure the planning of dissemination activities and support the participants if they wish to participate in presenting the results. In the study, the researcher arranged the practicalities around the dissemination. Furthermore, it is important to celebrate the end of the project to say 'thank you' for their contribution and to bring the project to a close (Thoft, 2017).

The core of the model illustrates the role of the researcher, illustrating the importance of the researcher taking a clear role and level of responsibility in the collaboration, without promoting their own views over those of others. The researcher needs to Establish and develop a trusting committed relationship where people with early-stage dementia can share their experiences and opinions and where both they and the researcher commit to the collaboration. The researcher also has to support the participants' contribution without becoming too personal or emotional. Likewise, the researcher has to Balance the researcher, supporter, teacher and learner role. This means juggling between the leading and supportive roles to ensure the participants' involvement in the research and progress in the research process. In practice, this means constantly balancing between training participants in research skills and acting as a facilitator to their own research 
process, without leading it. The power of all those involved must be actively managed to create a constructive collaboration. Supporting peer-learning andsupport refers to assisting participants during the project work but can also lead to supporting their wider lives through sharing accounts of personal strategies between the participants. Interestingly, peer-support can also include the researcher (depending on their own experiences and training), further enhancing this element of collaboration. An example might include helping the researcher to manage the deadlines in the project. Finally, the researcher must Create a relaxed atmosphere, where the participants feel safe to express their opinions. This may include the use of humour to ensure all participants feel included in the activity (Thoft, 2017).

For both the participants and the researcher the collaboration was transformative. In the evaluative elements of the project participants noted that their understanding of dementia, and hearing about the experiences, advice and strategies of others in their group left them feeling better prepared for living with the condition. They felt empowered and rehabilitated through the work (Thoft, 2017).

For the researcher, the project offered new insights into the possibilities of collaborating with people with dementia. The three-month period of observation prior to the recruitment taught the researcher how people with dementia learn in a school environment. The project work also showed how knowledge about dementia was essential to understand and actively respond to their situation. This was a continuous process of change and adaptation within the process, ensuring that the collaboration was participatory, and not getting too demanding for the participants. This required constant reflection on the part of the researcher, enabling adaptations even within the sessions themselves to facilitate participation.

\section{Discussion: The Balanced participation Model: contributions and areas for future research}

The Balanced Participation Model is an alternative model for participatory research collaborating with people with early-stage dementia. It differentiates from its predecessors (Parkes et al., 2014; Dupuis et al., 2012) by incorporating the development of projects alongside the research methods training as it is delivered, ensuring that learning is used in 'real time' during the project, whilst it is still fresh in participants' minds. The model illustrates a complete research process from recruitment to dissemination, incorporating an evaluation of the research process. 
In addition, it describes the full process of recruiting, gaining consent and training people with early-stage dementia.

The project has signalled the way in which research training and participatory research can go hand in hand as a continuous process, where research is conducted in real time with the concurrent training. This is an important aspect of a model designed to meet the needs of people with dementia who may find it challenging to retain training-related information. In this way, the model supports their participation 'in the moment' rather than training them for future research opportunities as previous models have advocated (Parkes et al., 2014). This leads to a more structured participatory research process, allowing for and offering support in both the training and research process. In this way, it is not necessary to rely on long-term learning for the participants to contribute to research, which is vital when involving people with early-stage dementia because of the progressive cognitive impairment.

The application of the model is realistic where research is adequately planned, and the researcher can spend time building rapport with their potential participant group. Research of this kind can be time-consuming, because each step in the process must be modified to the participants' competences and needs, and these will change as the dementia progresses. Building flexibility into a model of this kind is imperative to enable adaptation and a supportive whilst engaging environment. Researchers need to establish constructive and trusting relationships with participants to give collaborative research the best chance of success. This means the researcher has to balance the project work and data collection at the same time, so the participants feel safe and confident about raising their voice. Prioritising and simplifying the processes involved supports non-tokenistic participation.

In addition to the reflections offered above, it is important to consider the role of the researcher in participatory research. To engage fully with a process of this kind, researchers should have an awareness of the different degrees of participation. This is important for two reasons. First, only through understanding relevant literature underpinning participatory research can researchers align their own values and expectations to the process. Second, working to balance a participatory approach with the needs of any lesser-heard participant group - in this case people with dementia - demands a constant balancing act to ensure that their aspirations are at the heart of the project whilst still producing robust research outcomes (McKeown, 2010; Thoft, 2017). One of the main challenges arising from this research was the 
constant balancing between different roles for the researcher. Existing advocates of participatory research argue the importance of participants having the same rights as the researcher when it comes to decision-making (Bergold \& Thomas, 2012). In practice, the researcher then has to weigh the balance of control within the research context reflexively as it unfolds. Challenges may also arise where some participants are more vocal than others or, in the case of this participant group, the speed of progression within discussions moves at too fast a pace for some participants to follow. In instances like these, the researcher is placed in the position of having to respond, ensuring that the heterogeneous needs of the participants as a group are met, whilst not exerting absolute power over the process. In addition, researchers, by the nature of their role, will have experience of framing and conducting research which participants do not, and their knowledge and skills can be put to good use supporting the development of a manageable, realistic project. Within this study, these fluctuating issues served to place the researcher simultaneously in the roles of 'teacher', 'researcher' 'learner' and 'supporter'. The study has shown how significant the role of the researcher is in participatory research when collaborating with people with early-stage dementia. This includes ethical considerations and moral sensitivity about the participants' involvement enabling inclusion and shared decision-making. This includes critical considerations of existing guidelines and frameworks to ensure they do not exclude rather than include people with early-stage dementia.

Questions are raised within participatory research literature about the nature of consent that is needed (Dewing, 2007). Where participants are acting as coresearchers, conducting a consent process may undermine their power in the process, as consent is normally used only for recruiting participants. On the other hand, the requirements of statutory bodies and ethics committees need to be considered within decision-making here. The Helsinki declaration (WMA, 2013), states that research only is conducted with vulnerable groups if no-one else can act on their behalf and if it is beneficial for the group. Thus, a voluntarily written consent is required (WMA, 2013). Within this study, consent was used to ensure that people with dementia agreed to participate in the research as both coresearchers and as participants. It was important to demonstrate that they understood the information and voluntarily consented to the project, which would have been difficult to evidence in line with relevant authority requirements without having a written consent process in place. To easily allow them to withdraw at any time during the project this written consent was followed up with an ongoing verbal 
process, conducted in a way that suited rather than patronised participants to guarantee true informed consent at each project session. In practice this took the form of a verbal check-in at the start of each session. The experiences gleaned throughout the study show it is possible for people with early-stage dementia to give informed consent both written and verbally when it is adjusted (e.g. with the use of repetition to aid short-term memory loss).

Furthermore, ethical considerations and moral sensitivity during participatory research are central to ensuring that participants are not burdened unnecessarily. Again, here the researcher must balance between the ethos of participatory research and ethical considerations, alongside what is practicably possible. This means balancing between enabling and limiting the participation of the participants to guarantee their continued involvement. Likewise, in the dissemination of the results it is vital to ensure that the key messages are shared in ways that do not uphold existing stigma in society, and to remain true to the contributions of the participants themselves (Thoft, 2017). Participatory research risks disempowering rather than empowering the participants if the researcher does not ensure their ethically sound participation and robust design and outcomes from the research itself.

\section{Limitations}

The involvement of the researcher in studies of this kind can be a central issue of debate and critique. At the outset of the study, the researcher drew from existing literature on the remit and boundaries of participatory research, which often promote participant-instigated research as a primary objective (Arnstein, 1969). Within this research, a balancing of the multi-faceted nature of the researcher's role at times led to a greater input than had been anticipated at the outset. This involvement was constantly re-evaluated with participants themselves, and open discussions ensued about the best way to support them to adapt the process to their varied - and changing situation. More research and reflection are needed about how to guarantee the participants of any research project the most influence in participatory studies, whilst also enabling researchers to respond to their needs.

The participatory research projects arising from the study involved people with dementia both as researchers and participants, and we are aware that this challenge the often pre-conceived nature of 'traditional' research. This reflects the discussion at the outset of the paper regarding the challenges associated with conducting 
participatory research which, in and of itself, is a multi-faceted and changing conceptual term in both application and understanding. The variations of concepts and terminologies which feed into it, can limit consistency and clarity within the field. We hope that the reflections offered here through The Balanced Participation Model offer useful contributions to these discussions.

The training in research skills may also be critiqued for not focusing on long-term learning. The study does not, therefore, offer direct recommendations for involving people with early-stage dementia in research which requires a focus on long-term memory. Furthermore, the training was modified to the exact type of project conducted and the participants' capabilities. Whilst in some respects this offers advantages in enabling participants to fully engage on their own terms, the authors recognise that it may not always be possible for researchers - often working with constraints in relation to time and funds - to plan and conduct research in this way.

\section{Conclusion}

This paper has explored a range of benefits and challenges in collaborating with people with early-stage dementia in participatory research, offering a range of reflections and suggested guidance to underpin research of this kind. A new participatory research model has been proposed, designed specifically for working with people with dementia: The Balanced participation Model. The development of positive approaches to conducting research with people with dementia enables their voices to be heard in research. Furthermore, it can empower and rehabilitate people with early-stage dementia. Participating in the research process in this way can offer researchers and people with dementia rich insights into strategies for living and coping with the condition through sharing experiences and advices. This type of research is not without its challenges as the researcher has to give power to the participants and manage four different roles; a researcher, teacher, supporter and learner role in the research process. However, The Balanced Participation Model has been designed to enable more people with early-stage dementia to be engaged in research in the future, with the aim of honing our knowledge and skills as researchers to enable their voices to be heard. This will hopefully contribute with more relevant praxis related research that can nuance the picture of dementia in research and society. 
Keywords: dementia, participatory research model, involvement, research, participation

\section{Conflicts of interest}

The Authors declare that there is no conflict of interest.

\section{References}

Alzheimer Europe. (2013). The ethical issues linked to the perceptions and portrayal of dementia and people with dementia - ethical issues in practice - ethics alzheimer europe. Retrieved from http://www.alzheimereurope.org/Ethics/Ethical-issues-in-practice/The-ethical-issues-linked-to-theperceptions-and-portrayal-of-dementia-and-people-with-dementia

Arnstein, S. (1969). A ladder of citizen participation. Journal of the American Institute of Planners, 35, 216-224.

Barnes, C., \& Mercer, G. (1997). Chapter 1. Doing disability research (pp. 1-14). Leeds: The Disability Press.

Braun, V., \& Clarke, V. (2006). Using thematic analysis in psychology. Qualitative Research in Psychology, 3(2), 77-101. 
Bergold, J., \& Thomas, S. (2012). Participatory research methods: A methodological approach in motion. Qualitative Social Research, 13(1)

Blumenthal, D. S. (2011). Is community-based participatory research possible? Am J Prev Med, 40(3), 386-389.

Burns, D., Hyde, P., Killett, A., Poland, F., \& Gray, R. (2014). Participatory organizational research: Examining voices in the co-production of knowledge. British Journal of Management, 25, 133-144.

Carey, M. (2010). Should I stay or should I go? practical, ethical and political challenges to "service user" participation within social work research. Qualitative Social Work, 10(2), 224-243.

Clare, L., \& Woods, B. (2008). Cognitive rehabilitation and cognitive training for early-stage alzheimer's disease and vascular dementia (review). The Cochrane Library, (4), 1-39.

Clarke, C. L., \& Keady, J. (2002). Getting down to brass tasks. A discussion of data collection with people with dementia. In H. Wilkinson (Ed.), The perspectives of people with dementia - research methods and motivations (pp. 25-46). London: Jessica Kingsley Publishers. 
Conder, J. (2011a). Reflections on a participatory project: The rewards and challenges for the lead researchers. Journal of Intellectual Developmental Disability, 36(1), 39-48. doi:10.3109/13668250.2010.548753

Conder, J. (2011b). Reflections on a participatory project: The rewards and challenges for the lead researchers. Journal of Intellectual Developmental Disability, 36(1), 39-48. doi:10.3109/13668250.2010.548753

Cornwall, A. (2008). Unpacking participation: Models, meanings and practices. Community Development Journal, 43(3), 269-283.

Cornwall, A., \& Jewkes, R. (1995). What is participatory research? Social Science \& Medicine, 41(12), 1667-1676. doi:http://dx.doi.org.ez-

\section{scv.statsbiblioteket.dk:2048/10.1016/0277-9536(95)00127-S}

Dewar, B. (2005). Beyond tokenistic involvement of older people in research - a framework for future development and understanding. Journal of Clinical Nursing, 14(1), 48-53.

Dewing, J. (2007). Participatory research: A method for process consent with persons who have dementia. Dementia, 6(1), 11-25. doi:10.1177/1471301207075625 
Dupuis, S. L., \& Gillies, J. (2014). Learning as a vehicle for individual and social transformation. Therapeutic Recreation Journal, XLVIII(2), 113-134.

Dupuis, S. L., Gillies, J., \& Carson, J. (2012). Moving beyond patient and client approaches: Mobilizing authentic partnerships in dementia care, support and services. Dementia, 11(4), 427-452.

Ehde, D. M., Wegener, S. T., Williams, R. M., Ephraim, P. L., Stevenson, J. E., Isenberg, P. J., \& MacKenzie, E. J. (2013). Developing, testing, and sustaining rehabilitation interventions via participatory action research. Archives of Physical Medicine and Rehabilitation, 94(1), 30-42. doi:http://dx.doi.org/10.1016/i.apmr.2012.10.025

Faulkner, A. (2004). The ethics of survivor research: Guidelines for the ethical conduct of research carried out by mental health service users and survivors | joseph rowntree foundation. Retrieved from http://www.jrf.org.uk/publications/ethics-survivor-research-guidelines-ethicalconduct-research-carried-out-mental-health-

Fudge N., Wolfe, C. D. A., \& McKevitt, C. (2007). Involving older people in health research. Age and Ageing, 38(5), 492-500. 
Hanson, E., Magnusson, L., Arvidsson, H., Claesson, A., Keady, J., \& Nolan, M. (2007). Working together with persons with early stage dementia and their family members to design a user-friendly technology-based support service. Dementia, 6(3), 411-434.

Hellström, I., Nolan, M., \& Lundh, U. (2007). Ethical and methodological issues in interviewing persons with dementia. Nursing Ethics, 14(5), 608-619. doi:10.1177/0969733007080206

Hubbard, G., Downs, M., \& Tester, S. (2003). Including the perspectives of older people in institutional care during the consent process. In H. Wilkinson (Ed.), The perspectives of people with dementia: Research methods and motivations (pp. 63-82). London: Jessica Kingsley Publishers.

INVOLVE. (2018). Induction materials for research staff new to public involvement. Retrieved from http://www.invo.org.uk/resource-centre/learning-anddevelopment/whats-on-this-site/get-started/induction-materials-for-researchstaff-new-to-public-involvement/

Keady, J., Williams, S., \& Hughes-Robets, J. (2005). Emancipatory practice development through life-story work: Changing care in a memory clinic in north wales. Practice Development in Health Care, 4(4), 203-212. 
Kelly, S., Lafortune, L., Hart, N., Cowan, K., Fenton, M., \& Brayne, C. (2015).

Dementia priority setting partnership with the james lind alliance: Using patient and public involvement and the evidence base to inform the research agenda. Age Ageing, 44(6), 985-993.

Kitwood, T. (1997). Dementia reconsidered: The person comes first. Buckingham: Open University Press.

Knight, B. G., Lutzky, S. M., \& Macofsky-Urban, F. (1993). A meta-analytic review of interventions for caregiver distress: Recommendations for future research. The Gerontologist, 33(2), 240-248.

Knobzi, N., \& Flicker, S. (2010). Lessons learned from undertaking community-based participatory research dissertations: The trials and triumphs of two junior health scholars. Progress in Community Health Partnerships: Research, Education and Action, 4(4), 347-356.

Law, E. (2013). Dementia research - what do different public groups want? A survey by the scottish dementia clinical research network. Dementia, 12(1), 23-28. doi:10.1177/0142723711420309

Littlechild, R., Tanner, D., \& Hall, K. (2015). Co-research with older people: Perspectives on impact. Qualitative Social Work, 14(1), 18-35. 
McKeown, J. (2010). Actively involving people with dementia in qualitative research. Journal of Clinical Nursing, 19(13-14), 1935-43. doi:10.1111/j.13652702.2009.03136.x

Mckillop, J. (2004). Make it easy on yourself!: Advice to researchers from someone with dementia on being interviewed. Dementia, 3(2), 117-125. doi:10.1177/1471301204042332

McParland, P., Kelly, F., \& Innes, A. (2017). Dichotomising dementia: Is there another way? Sociology of Health \& IIIness, 39(2), 258-269.

Milligan, C. (2015). Participatory research: Background and outlook. Retrieved from http://www.lancaster.ac.uk/researchethics/5-2-outlook.html

Nomura, M. (2009). Empowering older people with early dementia and family caregivers: A participatory action research study. International Journal of Nursing Studies, 46(4), 431-441. doi:10.1016/j.ijnurstu.2007.09.009

Parkes, J. H., Pyer, M., Wray, P., \& Taylor, J. (2014). Partners in projects: Preparing for public involvement in health and social care research. Health Policy, 117(3), 399-408. doi:http://dx.doi.org.ezscv.statsbiblioteket.dk:2048/10.1016/i.healthpol.2014.04.014 
Pipon Young, F. (2012). I'm not all gone, I can still speak: The experiences of younger people with dementia. an action research study. Dementia, 11(5), 597-616. doi:10.1177/1471301211421087

Reed, J., Cook, G., Bolter, V., \& et al. (2006). Older people 'Getting things done' involvement in policy and planning initiatives. York: Joseph Rowntree Foundation.

Roy, A. (2012). Avoiding the involvement overdose: Drugs, ethnicity and participatory research practice. Critical Social Policy, 32(4), 636-654.

Stacciarini, J., Shattell, M., Coady, M., \& Wiens, B. (2011). Review: Community-based participatory research approach to address mental health in minority populations. Community Mental Health Journal, 47(5), 489-497. doi:10.1007/s10597-010-9319-z

Staniszewska, S. (2009). Patient and public involvement in health services and health research: A brief overview of evidence, policy and activity. Journal of Research in Nursing, 14(4), 295-298. doi:10.1177/1744987109106811

Tandon, R. (2005). Participatory research: Revisiting the roots. New Delhi: Mosaic Books. 
Tanner, D. (2012). Co-research with older people with dementia: Experience and reflections. Journal of Mental Health, 21(3), 296-306.

doi:10.3109/09638237.2011.651658

Thoft, D. S. (2017). Involving people with earlystage dementia in qualitative research about their lifeworld perspectives. Aalborg: Aalborg University Press.

Traina, I. (2014). Social inclusion of vulnerable groups through participatory and emancipatory approaches. implementing active citizenship and socially innovative actions in the framework of civil \& human rights model of disability Alma Mater Studiorum Università di Bologna. Dottorato di ricerca in Scienze pedagogiche, 26 Ciclo. DOI 10.6092/unibo/amsdottorato/6481.

VUK. (2013). Specialskolen for voksne. Retrieved from http://vuk-

\section{aalborg.skoleporten.dk/sp}

Ward, P. R. (2009). Critical perspectives on consumer involvement in health research: Epistemological dissonance and the know-do gap. Journal of Sociology, $46(1), 63-82$.

Ward A., Thoft D.S., Lomax H., Parkes J. (2018). A visual and creative approach to exploring people with dementia's experiences of being students at a school in 
Denmark. Dementia: the international journal of social research and practice, $\mathrm{p}$.

Ward, A.; Sorensen, K. A.; Kousgaard, H.; Thoft, D. S.; Parkes, J. (2018) "Going back to school - An opportunity for lifelong learning for people with dementia in Denmark (Innovative Practice)". Dementia: the international journal of social research and practice, p. 1-8.

Wilkinson, H. (2002). Including people with dementia in research: Methods and motivation. In H. Wilkinson (Ed.), The perspectives of people with dementia: Research methods and motivations (pp. 9-24). London: Jessica Kingsley Publishers.

Wilkinson, H., \& Hubbard, G. (2003). Exploring innovative ways of seeking the views of older people in health and social care research. Research, Planning and Policy, 21(2), 1-4.

Winblad, B., Amouyel, P., Andrieu, S., Ballard, C., Brayne, C., Brodaty, H., . . Wimo, A. (2016). Defeating alzheimer's disease and other dementias: A priority for european science and society. The Lancet Neurology, 15(5), 455-532. 
World Medical Association. (2013). WMA declaration of Helsinki - ethical principles for medical research involving human subjects. Retrieved from http://www.wma.net/en/30publications/10policies/b3/

Yu, F. (2009). Cognitive training for early-stage alzheimer's disease and dementia. Journal of Gerontological Nursing, 35(3), 23-9. 